\title{
ARTICLE \\ Metabolism and disposition of pyrotinib in healthy male volunteers: covalent binding with human plasma protein
}

\author{
Jian Meng ${ }^{1}$, Xiao-yun Liu ${ }^{1}$, Sheng Ma ${ }^{2,3}$, Hua Zhang ${ }^{2,3}$, Song-da Yu' ${ }^{1}$ Yi-fan Zhang ${ }^{1}$, Mei-xia Chen ${ }^{4}$, Xiao-yu Zhu ${ }^{4}$, Yi Liu ${ }^{4}$, Ling Yi ${ }^{2,3}$, \\ Xiao-liang Ding ${ }^{2,3}$, Xiao-yan Chen ${ }^{1}$, Li-yan Miao ${ }^{2,3}$ and Da-fang Zhong ${ }^{1}$
}

Pyrotinib is a novel irreversible EGFR/HER2 dual tyrosine kinase inhibitor that is used to treat HER2-positive breast cancer. In this study we investigated the metabolism and disposition of pyrotinib in six healthy Chinese men after a single oral dose of $402 \mathrm{mg}$ of $\left[{ }^{14} \mathrm{C}\right]$ pyrotinib. At $240 \mathrm{~h}$ postdose, the mean cumulative excretion of the dose radioactivity was $92.6 \%$, including $1.7 \%$ in urine and $90.9 \%$ in feces. In feces, oxidative metabolites were detected as major drug-related materials and the primary metabolic pathways were O-depicoline (M1), oxidation of pyrrolidine (M5), and oxidation of pyridine (M6-1, M6-2, M6-3, and M6-4). In plasma, the major circulating entities identified were pyrotinib, SHR150980 (M1), SHR151468 (M2), and SHR151136 (M5), accounting for 10.9\%, 1.9\%, $1.0 \%$, and $3.0 \%$, respectively, of the total plasma radioactivity based on the $\mathrm{AUC}_{0-\infty}$ ratios. Approximately $58.3 \%$ of the total plasma radioactivity $\mathrm{AUC}_{0-\infty}$ was attributed to covalently bound materials. After incubation of human plasma with $\left[{ }^{14} \mathrm{C}\right]$ pyrotinib at $37{ }^{\circ} \mathrm{C}$ for $2,5,8$, and $24 \mathrm{~h}$, the recovery of radioactivity by extraction was $97.4 \%, 91.8 \%, 69.6 \%$, and $46.7 \%$, respectively, revealing covalent binding occurred independently of enzymes. A group of pyrotinib adducts, including pyrotinib-lysine and pyrotinib adducts of the peptides Gly-Lys, Lys-Ala, Gly-Lys-Ala, and Lys-Ala-Ser, was identified after $\mathrm{HCl}$ hydrolysis of the incubated plasma. Therefore, the amino acid residue Lys190 of human serum albumin was proposed to covalently bind to pyrotinib via Michael addition. Finally, the covalently bound pyrotinib could dissociate from the human plasma protein and be metabolized by oxidation and excreted via feces.

Keywords: pyrotinib; EGFR/HER2 dual tyrosine kinase inhibitor; breast cancer; drug metabolism; drug disposition; human plasma; covalent binding

Acta Pharmacologica Sinica (2019) 40:980-988; https://doi.org/10.1038/s41401-018-0176-6

\section{INTRODUCTION}

Pyrotinib (SHR1258) is a novel irreversible epidermal growth factor receptor/human epidermal growth factor receptor 2 (EGFR/HER2) dual tyrosine kinase inhibitor. Recently, pyrotinib was developed for the treatment of HER2-positive breast cancer in China and the United States [1]. In the first-in-patient study, the most common adverse effects were grade I/II gastrointestinal symptoms, such as diarrhea. The incidence and severity of diarrhea were dosedependent and clinically manageable up to $400 \mathrm{mg}$. The majority of incidences were transient and occurred in the first cycle. In Chinese patients with HER2-positive metastatic breast cancer, the best objective response rates were 55.6 and $87.5 \%$, and the median progression-free survival rates were 31.9 and 59.7 weeks, respectively, for the $320-\mathrm{mg}$ and $400-\mathrm{mg}$ dose cohorts [2]. Data from subsequent clinical investigations demonstrated that $400 \mathrm{mg}$ pyrotinib once daily in combination with capecitabine was generally safe and well tolerated with an encouraging antitumor response when administered to HER2-positive breast cancer patients [1]. Considering its significant clinical value, pyrotinib received a priority review and was recently approved by the China Food and Drug Administration.
The plasma pharmacokinetics of pyrotinib were characterized in patients during a phase I clinical study [2]. After the first dose of pyrotinib at $400 \mathrm{mg}$, the absorption of pyrotinib was relatively slow with a median $t_{\max }$ of $4.00 \mathrm{~h}$. The multiple-dose plasma concentration reached a steady state on day 8 . The exposure on study day 28 was 1.22 -fold increased compared with that of the single-dose exposure. These results suggest that pyrotinib does not significantly accumulate after repeated daily administration. Our previous study demonstrated that pyrotinib was extensively metabolized in humans, and the principle metabolites were SHR150980 (Odepicolyl pyrotinib, M1), SHR151468 (O-depicolyl and pyrrolidine lactam pyrotinib, M2), and SHR151136 (pyrrolidine lactam pyrotinib, M5) (Fig. 1). Phenotyping experiments demonstrated that CYP3A4 is the most active enzyme responsible for the biotransformation of pyrotinib [3]. As an irreversible inhibitor, pyrotinib has an $\alpha, \beta$-unsaturated amide moiety that acts as a pharmacological warhead and has the potential to covalently bind to protein via Michael addition [4-9]. This feature could make the disposition of pyrotinib more complicated. The rational development of pyrotinib relies on deeply understanding the dispositional characteristics of pyrotinib in humans. Therefore, the objective of the present study

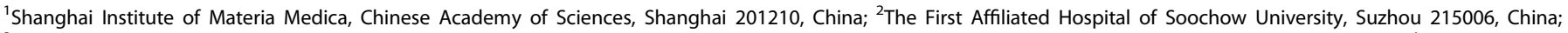

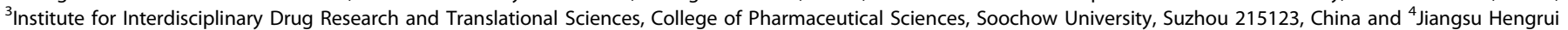
Medicine Co., Ltd, Lianyungang 222047, China

Correspondence: Li-yan Miao (miaolysuzhou@163.com) or Da-fang Zhong (dfzhong@simm.ac.cn)
}

Received: 11 June 2018 Accepted: 24 September 2018

Published online: 31 October 2018 
<smiles>[R16]O[R16]([H])(C)C</smiles>

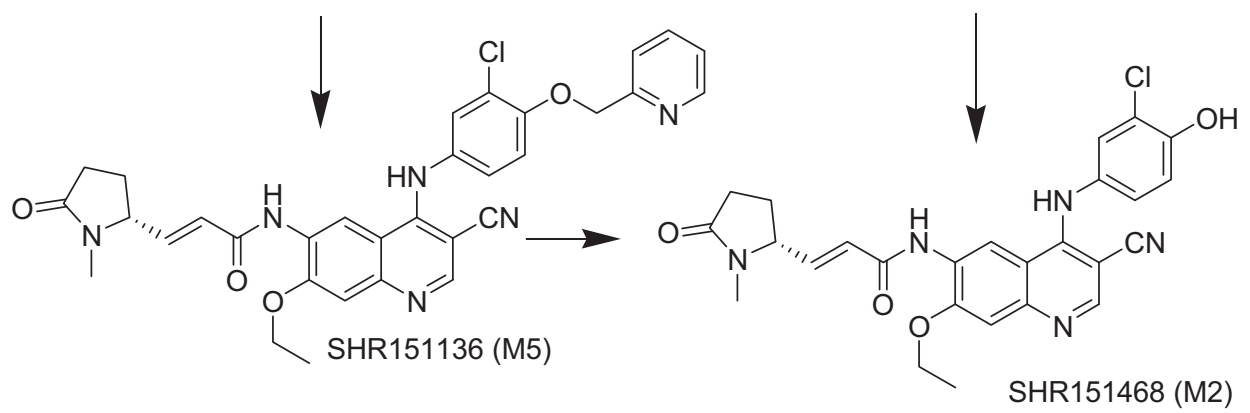

Fig. 1 Principal metabolic pathways of pyrotinib in humans reported in a previous study [3]

was to investigate the pharmacokinetics, metabolism, and excretion of pyrotinib in humans after the administration of a single oral dose of $\left[{ }^{14} \mathrm{C}\right]$ pyrotinib with a focus on the mechanism of the covalent binding of pyrotinib with human plasma protein.

\section{MATERIALS AND METHODS}

Study participants

Healthy male Chinese volunteers aged $25-38$ years old with a body mass index between 21 and $26 \mathrm{~kg} / \mathrm{m}^{2}$ and a body weight of 55-76 $\mathrm{kg}$ were enrolled in the study. The use of prescribed or nonprescribed concomitant medications was not permitted $14 \mathrm{~d}$ before and during the study. In addition, the use of medications with CYP450 enzyme-inducing properties was not permitted $30 \mathrm{~d}$ before the administration of pyrotinib [10]. Volunteers were also excluded if they had any intake of any product containing grapefruit, irregular bowel movements or abnormal values for clinical laboratory tests (hematology, serum chemistry, urinalysis, and stool analysis) or twelve-lead electrocardiography. The Independent Ethics Committee approved the protocol, and the study was conducted in accordance with the ethical principles that originate in the Declaration of Helsinki and are consistent with good clinical practices and applicable regulatory requirements. All patients provided written informed consent before enrollment.

\section{Study design}

This study was an open-label, single-center, single-dose study conducted at the First Affiliated Hospital of Soochow University (Suzhou, China). Plasma, urine, and feces were collected for $10 \mathrm{~d}$ after dosing, and the volunteers were discharged from the clinic when the following criteria were satisfied: the accumulated excreted radioactivity was greater than $80 \%$ of the administered radioactivity; the excreted radioactivity over 2 consecutive $d$ was less than $1 \%$ of the administered radioactivity; and the measured radioactivity in plasma collected over 2 continuous $d$ was less than two times that of the background. After the study, volunteers with clinically significant abnormal values were retained in the clinical facility or followed until normal levels were obtained.

Study medication

An oral suspension of $\left[{ }^{14} \mathrm{C}\right]$ pyrotinib was prepared by the dilution of high specific activity $\left[{ }^{14} \mathrm{C}\right]$ pyrotinib (WuXi AppTec, Shanghai,
China) with unlabeled pyrotinib and milled in a $0.5 \%$ carboxymethylcellulose sodium solution. The ${ }^{14} \mathrm{C}$ label was located on the nitrile group.

On day 1, following an overnight fast, each of the six volunteers received a single oral dose of $402 \mathrm{mg}$ of the pyrotinib suspension containing $5.55 \times 10^{6} \mathrm{~Bq}$ of $\left[{ }^{14} \mathrm{C}\right]$ pyrotinib. The vial used for drug administration was rinsed $3 \times$ with plain noncarbonated water, and the volunteers consumed the rinsing fluids along with additional plain noncarbonated water $(200 \mathrm{~mL})$. The volunteers were prohibited from drinking water for $1 \mathrm{~h}$ and fasted for $4 \mathrm{~h}$.

Pharmacokinetic evaluation

Blood samples $(\sim 4 \mathrm{~mL})$ were collected predose and at 1, 2, 3, 4, 5, $6,8,12,24,48,72,96,120,144,168,192,216$, and $240 \mathrm{~h}$ postdose into tubes containing $\mathrm{K}_{2}$ EDTA anticoagulant and centrifuged to determine the total radioactivity and the plasma pyrotinib, SHR150980, SHR151468, and SHR151136 concentrations (Jiangsu Hengrui Medicine Co., Ltd., Lianyungang, China). Extra blood samples $(\sim 10 \mathrm{~mL})$ were collected at $2,5,8,12,24$, and $48 \mathrm{~h}$ postdose for metabolite identification. Plasma pellets generated during the preparation of plasma (for metabolite identification) were used to further investigate the possible covalent binding of radioactive compounds to proteins. Plasma pellets were combusted using a Harvey OX-501 Biological Oxidizer (R. J. Harvey Instrument Corp., Tappan, New York, USA), and the total radioactivity was determined using a Packard Tri-Carb $3100^{\mathrm{TR}}$ liquid scintillation counter (PerkinElmer, Waltham, MA, USA). Urine and feces were collected predose and at 0-4, 4-8, 8-24, 24-48, 48-72, 72-96, 96-120, 120-144, 144-168, 168-192, 192-216, and 216-240 $\mathrm{h}$ postdose. All urine and feces samples were used for total radioactivity analysis. However, urine $(0-4,4-8$, and $8-24 \mathrm{~h}$ postdose) and feces (with radioactivity greater than $1 \%$ of the administered radioactivity) samples were selected and pooled for metabolic profiling. All samples collected were stored at $-15^{\circ} \mathrm{C}$ or less until analysis.

Bioanalytical procedures

Plasma samples were analyzed to determine the concentrations of pyrotinib, SHR150980, SHR151468, and SHR151136 using a validated liquid chromatography tandem mass spectrometry (LC-MS/MS) method. Total radioactivity was measured in plasma, urine, and feces using a Packard Tri-Carb 3100 TR liquid 
scintillation counter. Fecal residues were combusted using a Harvey OX-501 Biological Oxidizer prior to liquid scintillation counting. Metabolite profiling was performed using an 1100 HPLC system (Agilent Technologies, Inc., Santa Clara, CA, USA) coupled with an off-line TopCount NXT microplate scintillation and luminescence counter (PerkinElmer, Waltham, MA, USA). Separation was conducted using a Venusil $C_{18}$ column $(250 \mathrm{~mm} \times 4.6 \mathrm{~mm}$ I.D., $5 \mu \mathrm{m}$; Agela Corporation, Tianjin, China). A mobile phase gradient of $5 \mathrm{mmol} / \mathrm{L}$ ammonium acetate (containing $0.5 \%$ formic acid, A) and acetonitrile (B) was programmed linearly as follows: initiated with $20 \% \mathrm{~B}$, changed to $35 \%$ B over $20 \mathrm{~min}$, changed to $50 \%$ B over $30 \mathrm{~min}$, changed to $95 \%$ B over $5 \mathrm{~min}$, changed to $100 \%$ B over $10 \mathrm{~min}$ and held at $100 \%$ B for $5 \mathrm{~min}$. Then, the system was allowed to equilibrate for $15 \mathrm{~min}$ before the next injection. The flow rate of the mobile phase was $0.6 \mathrm{~mL} / \mathrm{min}$. HPLC fractions collected in a LumaPlate 96 -well plate were dried and counted using the TopCount NXT counter. Data were applied to construct radiochromatograms using the ARC data system (AIM Research Company, Hockessin, DE, USA). Metabolite identification was conducted on a Triple TOF $5600^{+}$MS system (AB SCIEX, Concord, Ontario, Canada) with a DuoSpray ion source in positive ion mode. Mass calibration was performed after every injection with a set of standards. Data were acquired using Analyst ${ }^{\oplus} \mathrm{TF}$ 1.6 software (AB SCIEX) and processed using MetabolitePilot ${ }^{\mathrm{TM}}$ 1.5 software (AB SCIEX).

Sample preparation for metabolic profiling

Feces. A 5-g portion of the pooled fecal homogenates was extracted using a three-step extraction procedure with $15 \mathrm{~mL}$ of acetonitrile/methanol (50/50) as the extraction solvent, and the supernatant was reduced to dryness under a stream of nitrogen at $40^{\circ} \mathrm{C}$. Dried fecal extracts were reconstituted in acetonitrile/water (50/50, $1000 \mu \mathrm{L})$. An 100- $\mu \mathrm{L}$ aliquot was injected into the HPLC system and analyzed by off-line radiodetection and Triple TOF $5600^{+} \mathrm{MS}$.

Urine. A 20- $\mathrm{mL}$ portion of the pooled urine samples was reduced to dryness under a stream of nitrogen at $40{ }^{\circ} \mathrm{C}$ and reconstituted in acetonitrile/water $(50 / 50,300 \mu \mathrm{L})$. A $100-\mu \mathrm{L}$ aliquot was injected into the HPLC system and analyzed by off-line radiodetection and Triple TOF $5600^{+}$MS.

Plasma. Pooled plasma samples were extracted by adding acetonitrile $(6 \mathrm{~mL})$ to plasma $(3 \mathrm{~mL})$. After the mixture was vortexed (1 $\mathrm{min}$ ) and centrifuged (3500× $\mathrm{g}, 5 \mathrm{~min}$ at room temperature), the remaining supernatant was reduced to dryness under a stream of nitrogen at $40^{\circ} \mathrm{C}$. The residues were reconstituted in acetonitrile/water $(50 / 50,300 \mu \mathrm{L})$, and a $100-\mu \mathrm{L}$ aliquot was injected into the HPLC system and analyzed by off-line radiodetection and Triple TOF $5600^{+} \mathrm{MS}$.

\section{Pharmacokinetic analysis}

Pharmacokinetic parameters of the total radioactivity, pyrotinib, SHR150980, SHR151468, and SHR151136 in plasma were derived using standard non-compartmental methods with Phoenix WinNonlin Professional Version 7.0 (Pharsight Corporation, Mountain View, CA, USA). The following pharmacokinetic parameters were assessed: maximum concentration $\left(C_{\max }\right)$; time to reach $C_{\max }$ $\left(T_{\max }\right)$; elimination half-life time $\left(t_{1 / 2}\right) ;$ area under the concentration-time curve (AUC) from time 0 to $48 \mathrm{~h}\left(\mathrm{AUC}_{0-48} \mathrm{~h}\right)$; AUC from time 0 to time of the last quantifiable concentration $\left(A \cup C_{0-\text { last }}\right)$; $A \cup C$ from time 0 to infinite time $\left(\mathrm{AUC}_{0_{-\infty}}\right)$ calculated as the sum of $A U C_{0 \text {-last }}$ and $C_{\text {last }} / \lambda_{z}$ in which $C_{\text {last }}$ is the last observed quantifiable concentration and $\lambda_{z}$ is the elimination half-life time to last quantifiable concentration; apparent volume of distribution $(\mathrm{Vz} / \mathrm{F})$ based on the terminal phase calculated as $\mathrm{D} /\left(\lambda_{\mathrm{z}} \times \mathrm{AUC}_{0-\infty}\right)$; and total drug clearance (CL/F) after extravascular administration calculated as $\mathrm{D} / \mathrm{AUC}_{0-\infty}$.
Safety evaluation

Safety and tolerability were evaluated throughout the study, which ranged from the time of obtaining informed consent to the end of the study or early withdrawal assessment. The physical examination, vital signs, clinical laboratory investigations (hematology, serum chemistry, urinalysis, and stool analysis), and twelvelead electrocardiography occurred before the administration of the study drug and at the end of the study assessment (after collection of the final fecal sample). The adverse effect severity was graded according to the criteria of CTCAE 4.03 [11].

Incubation of $\left[{ }^{14} \mathrm{C}\right]$ pyrotinib with human plasma, serum albumin or a1-acid glycoprotein and hydrolysis of human plasma by $\mathrm{HCl}$ Briefly, $\left[{ }^{14} \mathrm{C}\right.$ pyrotinib $(200 \mathrm{ng} / \mathrm{mL})$ was incubated with human plasma, serum albumin $(45 \mathrm{mg} / \mathrm{mL})$ (Sigma-Aldrich, St. Louis, MO, USA) or a1-acid glycoprotein $(0.70 \mathrm{mg} / \mathrm{mL})$ (Sigma-Aldrich) at $37^{\circ}$ C [12-14]. After incubation for $0,2,5,8$, and $24 \mathrm{~h}$, sample aliquots were removed, added to 2 volumes of acetonitrile, vortexed for 1 $\mathrm{min}$, and centrifuged at $14,000 \times g$ for $5 \mathrm{~min}$. The total radioactivity of the supernatant was determined using a Packard Tri-Carb $3100^{\mathrm{TR}}$ liquid scintillation counter to examine the extraction recovery of $\left[{ }^{14} \mathrm{C}\right]$ pyrotinib after incubation with human plasma, serum albumin, or a1-acid glycoprotein.

After incubation with $\left[{ }^{14} \mathrm{C}\right]$ pyrotinib for $24 \mathrm{~h}$, a $0.2-\mathrm{mL}$ aliquot of human plasma was also transferred into $1 \mathrm{~mL}$ of $\mathrm{HCl}$ solution $(2 \mathrm{~mol} / \mathrm{L})$ and incubated at $90^{\circ} \mathrm{C}$ for $2 \mathrm{~h}$ under stirring. At the end of the incubation, the mixture was neutralized by the addition of $1 \mathrm{~mL}$ of $2 \mathrm{~mol} / \mathrm{L} \mathrm{NaOH}$. Then, a $100-\mu \mathrm{L}$ aliquot was injected into the HPLC system and analyzed by on-line radiodetection (AIM Research Co., Hockessin, DE, USA) and Triple TOF $5600^{+}$MS.

Reversibility of pyrotinib covalent binding with plasma proteins The reversibility of pyrotinib covalent binding with plasma proteins was evaluated according to the method reported by Chandrasekaran et al [15]. After pyrotinib $(20 \mu \mathrm{g} / \mathrm{mL})$ was incubated for 0 and $6 \mathrm{~h}$ with human plasma at $37^{\circ} \mathrm{C}$, aliquots $(50 \mu \mathrm{L})$ were removed from the samples and analyzed to determine the concentration of pyrotinib using the LC-MS/MS method. After the 6-h incubation, human plasma was also transferred and extracted with methyl-tert-butyl ether (MTBE) (twice with 4.5 volumes). Then, aliquots $(100 \mu \mathrm{L})$ of the aqueous layer (plasma protein residue) were suspended in $10 \mathrm{~mL}$ of phosphate buffer $(0.1 \mathrm{M}, \mathrm{pH} 7.5)$ and sonicated for $10 \mathrm{~min}$. The mixtures were incubated with gentle shaking at $37^{\circ} \mathrm{C}$ to release the pyrotinib that was covalently bound to human plasma protein. After suspension for 0 and $16 \mathrm{~h}$, aliquots $(50 \mu \mathrm{L})$ were removed from the samples and analyzed to determine the concentration of pyrotinib using the LC-MS/MS method.

\section{RESULTS}

Safety

Two out of six volunteers in the safety analysis set experienced at least one adverse effect, which was occult blood in the stool with grade 1 severity. No clinically relevant changes were observed by physical examination, clinical laboratory analyses, or vital sign measurements.

\section{Pharmacokinetics}

The mean concentration-time profiles of total radioactivity, pyrotinib, SHR150980, SHR151468, and SHR151136 in plasma are presented in Fig. 2, and the related pharmacokinetic parameters are summarized in Table 1. After a single oral dose of $402 \mathrm{mg}$ of $\left[{ }^{14} \mathrm{C}\right]$ pyrotinib, the median time to maximum plasma concentration $\left(t_{\max }\right)$ for radioactivity, pyrotinib, SHR150980, SHR151468, and SHR151136 was $\sim 4 \mathrm{~h}$, and the maximum plasma concentration $\left(C_{\max }\right)$ was $396,99.0,16.3,10.2$, and $43.6 \mathrm{ng}$ eq. $/ \mathrm{mL}$, respectively. The exposure of total radioactivity $\left(\mathrm{AUC}_{0_{-\infty}}\right)$ was $18200 \mathrm{~h} \times \mathrm{ng}$ eq. $/ \mathrm{mL}$. 


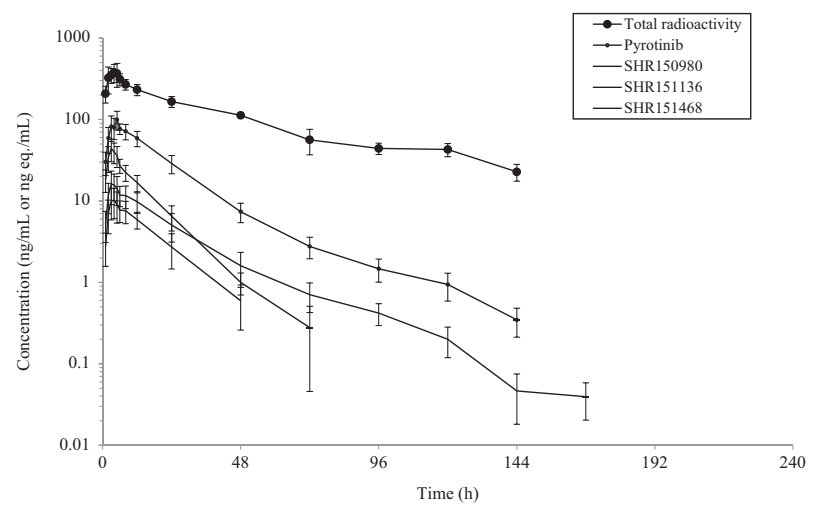

Fig. 2 Mean (+SD) concentration-time profiles of radioactivity, pyrotinib, SHR150980, SHT151468, and SHR151136 in plasma in six healthy male volunteers after a single oral dose of $402 \mathrm{mg}$ of $\left[{ }^{14} \mathrm{C}\right]$ pyrotinib

Pyrotinib, SHR150980, SHR151468, and SHR151136 accounted for only $10.9,1.9,1.0$, and $3.0 \%$, respectively, of the total plasma radioactivity based on geometric mean $A \cup C_{0-\infty}$ ratios. The mean plasma terminal half-life for radioactivity was $47.9 \mathrm{~h}$, which was increased compared with that for pyrotinib at $29.3 \mathrm{~h}$. The mean apparent total clearance and apparent volume of distribution for pyrotinib were $207 \mathrm{~L} / \mathrm{h}$ and $8570 \mathrm{~L}$, respectively, compared with $22.7 \mathrm{~L} / \mathrm{h}$ and $1460 \mathrm{~L}$, respectively, for the total plasma radioactivity.

Mass balance

In healthy volunteers $(n=6)$ after a single 402-mg oral dose of $\left[{ }^{14} \mathrm{C}\right]$ pyrotinib, the mean total radioactivity recovery was $92.6 \%$ (range 85.4-95.5\%). Fecal excretion was the predominant route of elimination, accounting for a mean of $90.9 \%$ (range $84.1-93.6 \%$ ) of the administered dose. The majority of the radioactivity in feces was excreted within $48 \mathrm{~h}$ after the dose, accounting for a mean of $81.5 \%$ (range $76.1-84.4 \%$ ) of the administered dose. Urinary excretion was minimal (mean 1.7\%; range 1.3-2.3\%) (Table 2).

Metabolite profiles in plasma, urine, and feces

The extraction procedures for plasma and feces were optimized to obtain the maximum recovery of radioactivity. The use of acetonitrile/methanol washes ensured that greater than $95 \%$ of pyrotinib and SHR150980, SHR151468, and SHR151136 spiked into control fecal homogenates could be recovered. However, the mean recovery of total radioactivity in feces postdose was only $39.3 \%$. Similarly, the recovery of total radioactivity in plasma postdose was $\sim 50 \%$ (Table 3), whereas greater than $90 \%$ of pyrotinib and SHR150980, SHR151468, and SHR151136 spiked into control plasma could be recovered using acetonitrile as the extraction solvent. This unextractable radioactivity was attributable to covalently bound materials [16-19]. The supernatants were analyzed by HPLC radiochromatography and high-solution MS for metabolite identification. Representative radiochromatograms are presented in Fig. 3. Three primary metabolic pathways for pyrotinib were distinguished based on the nature of the identified metabolites: O-depicoline (M1), the oxidation of pyrrolidine (M5) and the oxidation of pyridine (M6-1, M6-2, M6-3, and M6-4). Additional metabolites (M2, M7-1, M7-2, M7-3, M7-4, M7-5, and M8) were formed by combinations or further secondary metabolism of these main metabolites. In addition, some phase II metabolites, including cysteine adducts (M9-1, M9-2, M10-1, and M10-2) and N-acetylcysteine adducts (M12-1 and M12-2), were also detected (Fig. 4).

In feces, the major drug-related materials identified included pyrotinib, M5, M1, and M2, which accounted for $22.4,17.3,4.18$, and $12.0 \%$, respectively, of the peak area of the radiochromatogram of pooled feces. It should be noted that M2 and M6-5 were coeluted by

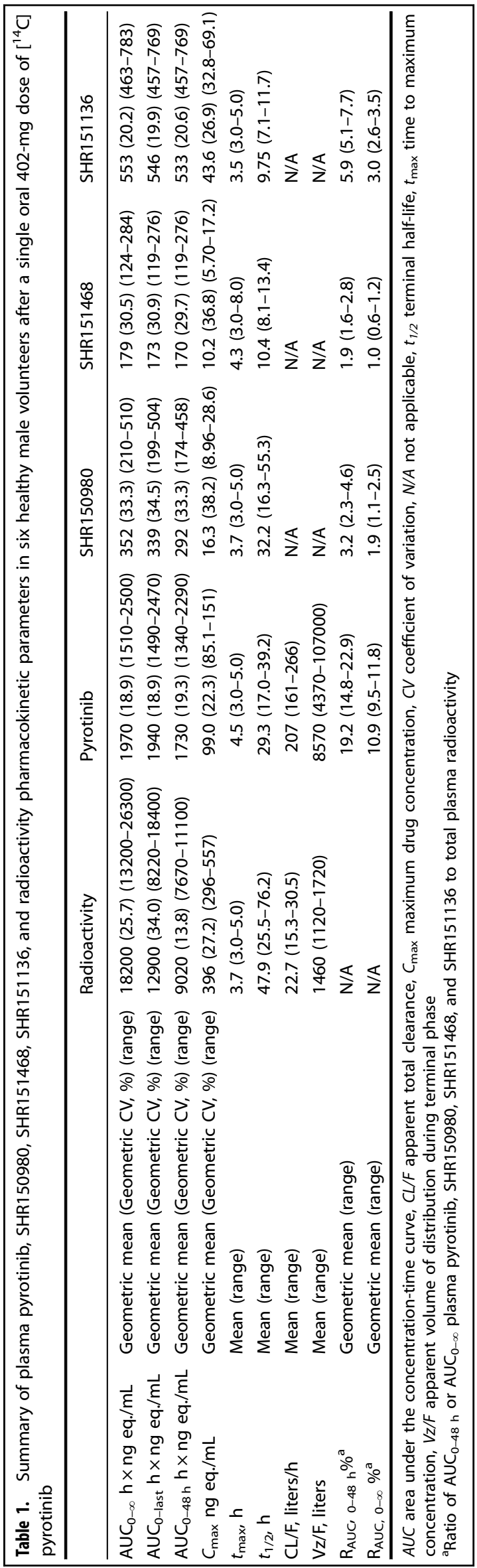


Table 2. Percentage of cumulative radioactivity recovered from six healthy male volunteers after a single $402-\mathrm{mg}$ oral dose of $\left[{ }^{14} \mathrm{C}\right] \mathrm{pyrotinib}$

\begin{tabular}{|c|c|c|c|c|}
\hline Time period & & Feces & Urine (\% dose) & Total \\
\hline $0-24 \mathrm{~h}$ & Mean (range) & $51.9(33.4-71.8)$ & $0.8(0.7-1.1)$ & $52.6(34.1-72.9)$ \\
\hline $0-48 \mathrm{~h}$ & Mean (range) & $81.5(76.1-84.4)$ & $1.1(0.9-1.6)$ & $82.6(77.2-85.4)$ \\
\hline $0-72 \mathrm{~h}$ & Mean (range) & $85.5(80.5-87.3)$ & $1.2(1.0-1.7)$ & $86.7(81.6-89.0)$ \\
\hline $0-96 \mathrm{~h}$ & Mean (range) & 87.9 (81.4-91.4) & $1.3(1.1-1.8)$ & $89.2(82.6-92.7)$ \\
\hline $0-120 \mathrm{~h}$ & Mean (range) & $89.1(82.3-92.4)$ & $1.4(1.2-1.9)$ & 90.5 (83.5-93.9) \\
\hline $0-144 \mathrm{~h}$ & Mean (range) & $89.8(83.2-92.7)$ & $1.5(1.2-2.0)$ & $91.3(84.4-94.3)$ \\
\hline $0-168 \mathrm{~h}$ & Mean (range) & $90.4(83.4-93.2)$ & $1.6(1.3-2.0)$ & 92 (84.7-94.9) \\
\hline $0-192 \mathrm{~h}$ & Mean (range) & $90.6(83.4-93.4)$ & $1.6(1.3-2.1)$ & $92.2(84.7-95.2)$ \\
\hline $0-216 \mathrm{~h}$ & Mean (range) & $90.8(83.8-93.6)$ & $1.7(1.3-2.3)$ & $92.5(85.1-95.5)$ \\
\hline $0-240 \mathrm{~h}$ & Mean (range) & 90.9 (84.1-93.6) & $1.7(1.3-2.3)$ & $92.6(85.4-95.5)$ \\
\hline
\end{tabular}

\begin{tabular}{|lll}
\hline Table 3. & Levels of covalently bound radioactivity in plasma \\
\hline Time & $\begin{array}{l}\text { Total radioactivity } \\
\text { (plasma) }\end{array}$ & $\begin{array}{l}\text { Covalent bound radioactivity } \\
\text { (plasma pellet) }\end{array}$ \\
\hline $\mathrm{h}$ & ng eq./mL & ng eq./mL (\%) ${ }^{\text {a }}$ \\
0 & BLQ & - \\
1.00 & 207 & - \\
2.00 & 324 & $95.8(29.3)$ \\
3.00 & 351 & - \\
4.00 & 378 & - \\
5.00 & 368 & $122(33.2)$ \\
6.00 & 311 & - \\
8.00 & 269 & $94.0(34.9)$ \\
12.0 & 232 & $101(43.5)$ \\
24.0 & 166 & $84.1(50.7)$ \\
48.0 & 112 & $73.0(65.2)$ \\
$C_{\max }$ & 378 & $122(32.3)$ \\
$t_{\max }$ & 4 & 5 \\
AUC $_{0-48} \mathrm{~h}$ & 9020 & $4132(45.8)$ \\
AUC $_{0-\infty}$ & 21700 & $12648(58.3)$ \\
\hline
\end{tabular}

apercentage of covalently bound radioactivity in plasma pellets accounting for total plasma radioactivity; $C_{\max }$ maximum drug concentration; $t_{\max }$ time to maximum concentration; AUC area under the concentration-time curve

HPLC. However, M2 was identified as the major metabolite by MS analysis. The concentrations of the phase II metabolites were very low at less than $1 \%$ of the peak area of the radiochromatogram of pooled feces. Combined with the radioactivity extraction efficiency (39.3\%) and the mass balance study results demonstrating that $92.6 \%$ of the administered dose was excreted via feces, the major drug-related materials pyrotinib, M5, M1, and $\mathrm{M} 2$ accounted for $8.00 \%, 6.18 \%, 1.49 \%$, and $4.29 \%$ of the dose, respectively. In urine, the major drug-related materials identified included pyrotinib, M6-2, M1, and M2, which accounted for $0.852 \%, 0.179 \%, 0.127 \%$, and $0.099 \%$ of the administered dose, respectively.

In addition to pyrotinib, the metabolites identified in plasma by MS analysis included M1, M2, M4, M5, M6-1, M6-2, and M6-5. However, only pyrotinib and M5 were detected by radiochromatography because most of the metabolites were generally below the detection limit of the radiodetector. Therefore, the metabolite profiles in plasma could only be qualitatively compared. The unextracted radioactivity in human plasma accounted for $29.3 \%$, $33.2 \%, 34.9 \%, 43.5 \%, 50.7 \%$, and $65.2 \%$ of total plasma activity at
$2,5,8,12,24$, and $48 \mathrm{~h}$, respectively. Based on the $\mathrm{AUC}_{0-\infty}$ ratios, unextracted radioactivity accounted for $\sim 58.3 \%$ of the total plasma radioactivity (Table 3 ).

Covalent binding of $\left[{ }^{14} \mathrm{C}\right]$ pyrotinib to human plasma protein, serum albumin, or a1-acid glycoprotein and hydrolysis of human plasma by $\mathrm{HCl}$

To explore the reason for the incomplete recovery of radioactivity from human plasma after the oral administration of $\left[{ }^{14} \mathrm{C}\right]$ pyrotinib, $\left[{ }^{14} \mathrm{C}\right]$ pyrotinib was incubated with human plasma, serum albumin, or a1-acid glycoprotein at $37^{\circ} \mathrm{C}$ for different amounts of time and extracted with acetonitrile. As shown in Table 4, the percentages of free $\left[{ }^{14} \mathrm{C}\right]$ pyrotinib (unbound, radioactivity recovery in acetonitrile extracts) in human plasma were $97.4 \%, 91.8 \%, 69.6 \%$, and $46.7 \%$, following incubation for 2, 5, 8, and $24 \mathrm{~h}$, respectively. Similarly, the percentages of free $\left[{ }^{14} \mathrm{C}\right]$ pyrotinib in serum albumin were $90.0 \%, 85.0 \%, 80.5 \%$, and $61.5 \%$ and the percentages of free $\left[{ }^{14} \mathrm{C}\right]$ pyrotinib in a1-acid glycoprotein were $82.5 \%, 81.5 \%, 78.5 \%$ and $78.0 \%$ following incubation for $2,5,8$, and $24 \mathrm{~h}$, respectively. The percent of covalent binding of pyrotinib with protein increased with increasing incubation time. After a 24-h incubation, the percentages of pyrotinib undergoing covalent binding with human plasma protein, serum albumin, and a1-acid glycoprotein were $53.3 \%, 38.5 \%$, and $22.0 \%$, respectively, suggesting that pyrotinib was mainly covalently bound with serum albumin and a1-acid glycoprotein to a less extent. Furthermore, these results revealed that the covalent binding of pyrotinib was independent on enzymes $[17,19]$.

To investigate the binding site, after $\left[{ }^{14} \mathrm{C}\right]$ pyrotinib-treated human plasma was directly hydrolyzed by $\mathrm{HCl}$ at $90^{\circ} \mathrm{C}$ for $2 \mathrm{~h}$, the sample was analyzed by HPLC radiochromatography (Fig. 5a). In addition to amide hydrolyzed pyrotinib (the latest eluted) and pyrotinib, the radioactive peaks identified by mass spectral data were a group of pyrotinib adducts that included pyrotinib-lysine $(\mathrm{m} / \mathrm{z} 731)$ and pyrotinib adducts of peptides Gly-Lys ( $\mathrm{m} / \mathrm{z} 788)$, LysAla ( $m / z$ 802), Gly-Lys-Ala ( $m / z$ 859), and Lys-Ala-Ser $(m / z ~ 889)$. The mass spectral data, including accurate molecular masses and the diagnostic product ions of these adducts, are summarized in Table 5 . Of note, protonated $\left[{ }^{14} \mathrm{C}\right]$ pyrotinib $(\mathrm{m} / \mathrm{z} 585)$ is a product ion for all peptide adducts listed in the table, which is evidence that pyrotinib was bound to these peptides. Proposed general fragmentation pathways of these pyrotinib peptide/lysine adducts are presented in Fig. $5 b$ and include the cleavage of the $a, \beta C-C$ of the carbonyl group to fragment II; cleavage of the $\mathrm{C}-\mathrm{N}$ bond of the peptide to pyrotinib to protonated pyrotinib I; and subsequent cleavage of the amide bond of pyrotinib to a fragment III.

Reversibility of pyrotinib covalent binding with plasma proteins The protein obtained from human plasma treated with pyrotinib after exhaustive extraction with MTBE was subsequently 
TopCount (CPM)

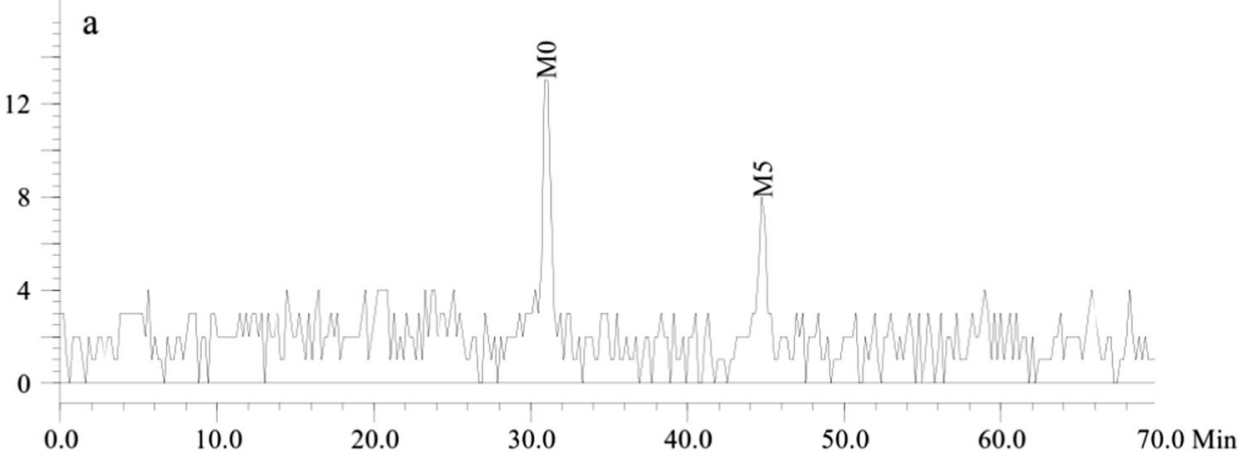

TopCount (CPM)
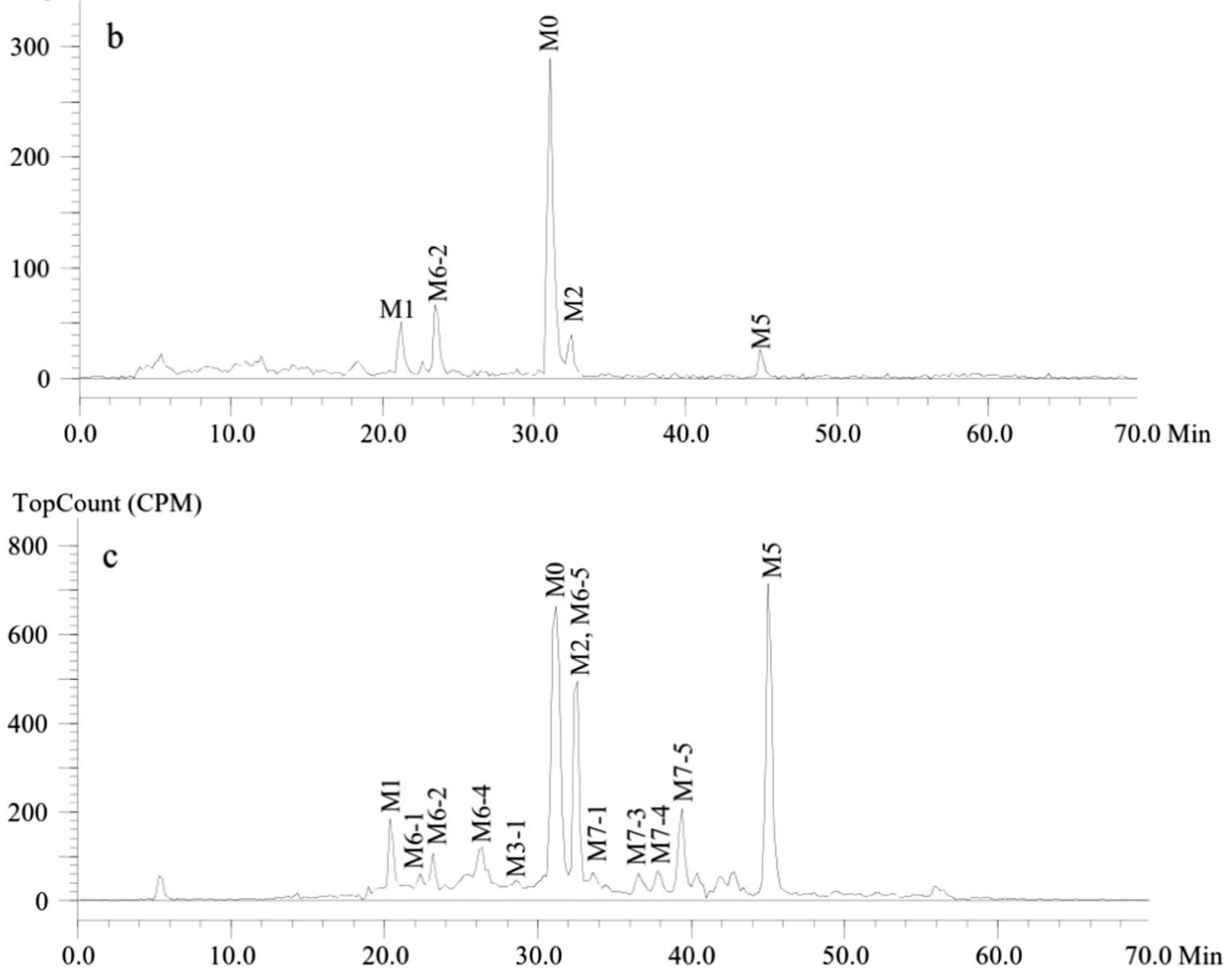

Fig. 3 Representative radiochromatograms of pyrotinib and metabolites in pooled plasma (a), urine (b), and feces (c)

reconstituted with phosphate buffer $(\mathrm{pH} 7.4)$ and incubated at $37^{\circ} \mathrm{C}$ to assess the reversibility of pyrotinib binding with plasma protein. The time course for the recovery of pyrotinib in plasma is presented in Table 6. After a 6-h incubation with human plasma, the extractable pyrotinib concentration was $16.6 \mu \mathrm{g} / \mathrm{mL}$. The results suggested that the amount of extractable pyrotinib was $83.0 \%$, and $17.0 \%$ remained in the protein. After resuspension of the treated protein in phosphate buffer $(\mathrm{pH} 7.4)$, the amount of extractable pyrotinib from protein was only $0.336 \mu \mathrm{g} / \mathrm{mL}$ at time 0 , and this amount increased to $7.15 \mu \mathrm{g} / \mathrm{mL}$ after incubation for $16 \mathrm{~h}$ at $37^{\circ} \mathrm{C}$, suggesting that $21.0 \%$ of covalently bound pyrotinib was released.

\section{DISCUSSION}

This study investigated the pharmacokinetic characteristics, the elimination routes and the metabolic profile of $\left[{ }^{14} \mathrm{C}\right]$ pyrotinib in healthy volunteers. After the oral administration of pyrotinib, most of the recovered dose was present in feces (90.9\%), with urinary excretion representing a minor elimination pathway (1.72\%). The overall recovery of $92.6 \%$ of the radioactive dose indicates a complete mass balance.

The values obtained for the time to reach the maximum plasma concentration, the maximum plasma concentration, the area under the plasma concentration-time curve and terminal half-life for pyrotinib in this healthy volunteer study were comparable with those observed in cancer patients [2]. The exposures of pyrotinib and its major metabolites, including SHR150980, SHR151468, and SHR151136, accounted for $10.9 \%, 1.9 \%, 1.0 \%$, and $3.0 \%$, respectively, of total plasma radioactivity based on $\mathrm{AUC}_{0_{-\infty}}$ ratios. Approximately $58.3 \%$ of total radioactivity was attributed to the radioactivity covalently bound to human plasma protein.

Data from the in vitro experiments indicated that $\left[{ }^{14} \mathrm{C}\right]$ pyrotinib, when incubated in human plasma at $37^{\circ} \mathrm{C}$, could not be extracted completely. The incomplete recovery of pyrotinib from plasma was caused by the covalent binding of pyrotinib with human plasma protein, which did not require the bioactivation of pyrotinib and occurred independently of enzymes. These results 


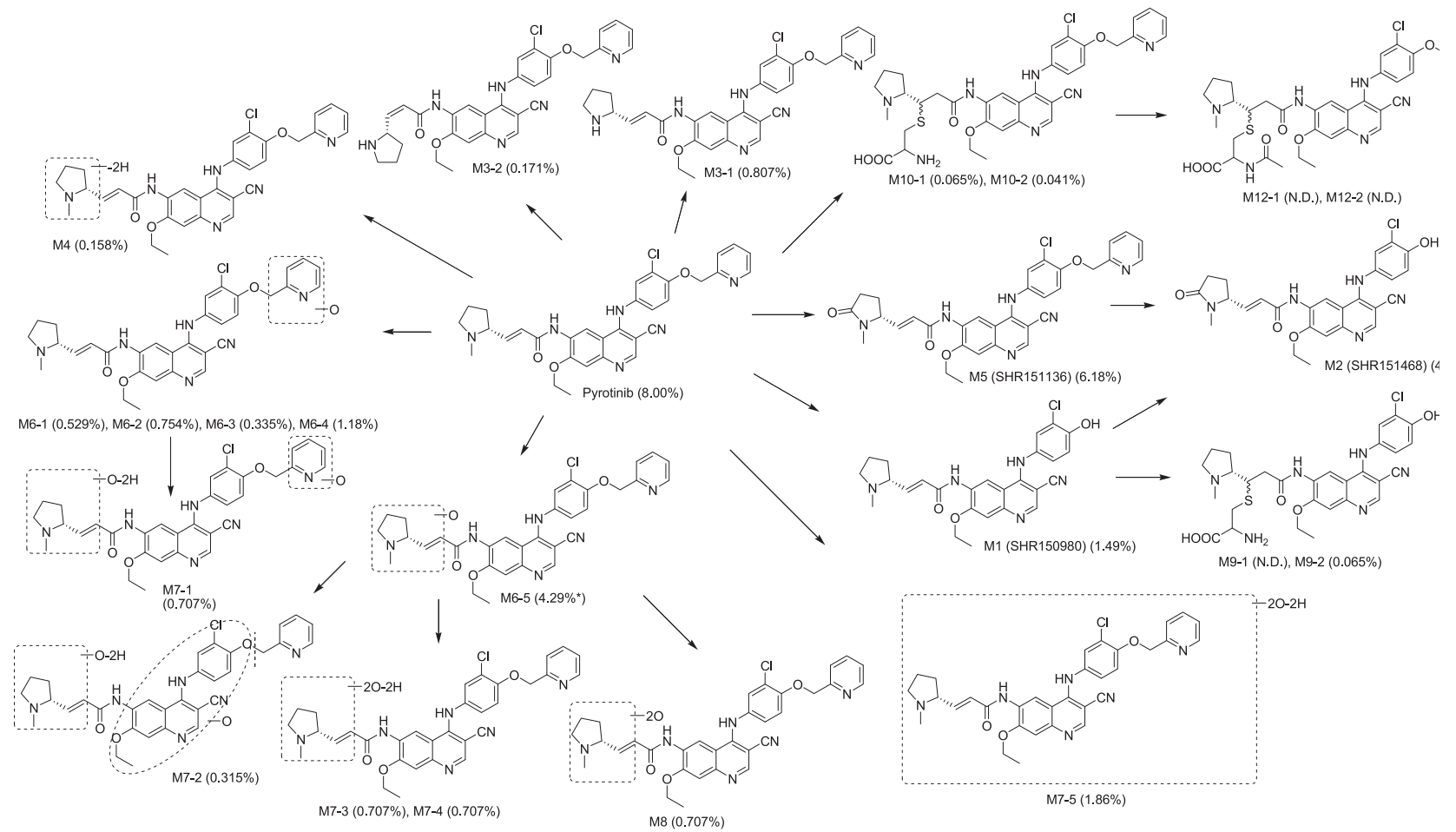

Fig. 4 Proposed metabolic pathways of pyrotinib in humans. (), percentage of metabolite in feces accounting for the dose administered (N.D., not detected by radiochromatography; asterisk M2 and M6-5 were coeluted by HPLC)

Table 4. Extractable radioactivity following incubation of $200 \mathrm{ng} / \mathrm{mL}$ $\left[{ }^{14} \mathrm{C}\right]$ pyrotinib with human plasma, serum albumin, or $\alpha 1$-acid glycoprotein at $37^{\circ} \mathrm{C}$ for different amounts of time

\begin{tabular}{llll}
\hline Time & Plasma & Serum albumin & $\alpha 1$-acid glycoprotein \\
\hline (h) & ng eq. $/ \mathrm{mL}(\%)^{\mathrm{a}}$ & $\mathrm{ng}$ eq. $/ \mathrm{mL}(\%)^{\mathrm{a}}$ & $\mathrm{ng} \mathrm{eq.} / \mathrm{mL}(\%)^{\mathrm{a}}$ \\
0 & $204(102)$ & $202(101)$ & $194(97.2)$ \\
2 & $195(97.4)$ & $180(90.0)$ & $165(82.5)$ \\
5 & $184(91.8)$ & $170(85.0)$ & $163(81.5)$ \\
8 & $139(69.6)$ & $161(80.5)$ & $157(78.5)$ \\
24 & $93.4(46.7)$ & $123(61.5)$ & $156(78.0)$ \\
\hline a percentage of extractable radioactivity accounting for the radioactivity \\
added into human plasma, serum albumin, or $\alpha 1$-acid glycoprotein
\end{tabular}

are not surprising because pyrotinib contains an $\alpha, \beta$-unsaturated amide moiety, which was pharmacologically designed to undergo Michael addition to covalently bind to the conserved, solventexposed cysteine residue present in some ErbB family members (Cys773 in epidermal growth factor receptor and Cys805 in Her-2) [1]. Similarly, the reactivity of the $a, \beta$-unsaturated amide entity renders pyrotinib covalently bound to other proteins in vivo, as suggested by the incomplete recovery of pyrotinib from human plasma after incubation. Furthermore, a group of pyrotinib adducts, including pyrotinib-lysine and pyrotinib adducts of peptides Gly-Lys, Lys-Ala, Gly-Lys-Ala, and Lys-Ala-Ser, was detected in the $\mathrm{HCl}$ digestion mixture of the incubated plasma. Wang et al reported that neratinib covalently bound to the Lys 190 residue of albumin, the most abundant protein in plasma. This findings was identified by a series of methods, including SDSPAGE, LC/MS, and the synthetic standard neratinib-lysine [17]. Therefore, based on the identification of these pyrotinib peptide/lysine adducts and the similarity in the structures of pyrotinib and neratinib, it could be proposed that pyrotinib covalently binds to the amino acid residue Lys190 of human serum albumin via Michael addition.

It could be hypothesized that this covalently bound radioactivity is eliminated via two pathways. One pathway is excretion as pyrotinib peptide/lysine adducts following catabolism of the albumin tether. In this context, the elimination of covalently bound radioactivity would depend mostly on the catabolism of tethered albumin molecules. In fact, the half-life of the radioactivity $(47.9 \mathrm{~h}, \sim 2 \mathrm{~d})$ was considerably shorter than the half-life of albumin in humans ( 19d) $[20,21]$. Furthermore, no pyrotinib peptide/lysine adducts were detected in human plasma after the oral administration of pyrotinib. These results indicate that the covalently bound radioactivity was eliminated by the way that covalently bound pyrotinib was dissociated from albumin followed metabolism [22, 23], which is reasonable because Michael additions are reversible [24]. Furthermore, pyrotinib was released from its protein adducts when it was suspended in phosphate buffer ( $\mathrm{pH} 7.4)$, as observed the in vitro incubation experiment. These results indicated that covalently bound pyrotinib could dissociate from the human plasma protein and be metabolized by oxidation and excreted via feces.

In summary, after a single oral dose of $402 \mathrm{mg}$ of $\left[{ }^{14} \mathrm{C}\right]$ pyrotinib in humans, pyrotinib and its three major metabolites, SHR150980, SHR151468, and SHR151136, accounted for $\sim 16.8 \%$ of the total plasma radioactivity. Approximately $58.3 \%$ of total radioactivity was attributed to the unextractable radioactivity, which appeared to be derived from pyrotinib covalently bound to human plasma protein. Covalent binding occurred independently of enzymes, and the amino acid residue Lys190 of human serum albumin was proposed to covalently bind to pyrotinib via Michael addition. Finally, the covalently bound drug-related materials appeared to dissociate from albumin and be excreted via feces following oxidative metabolism. 

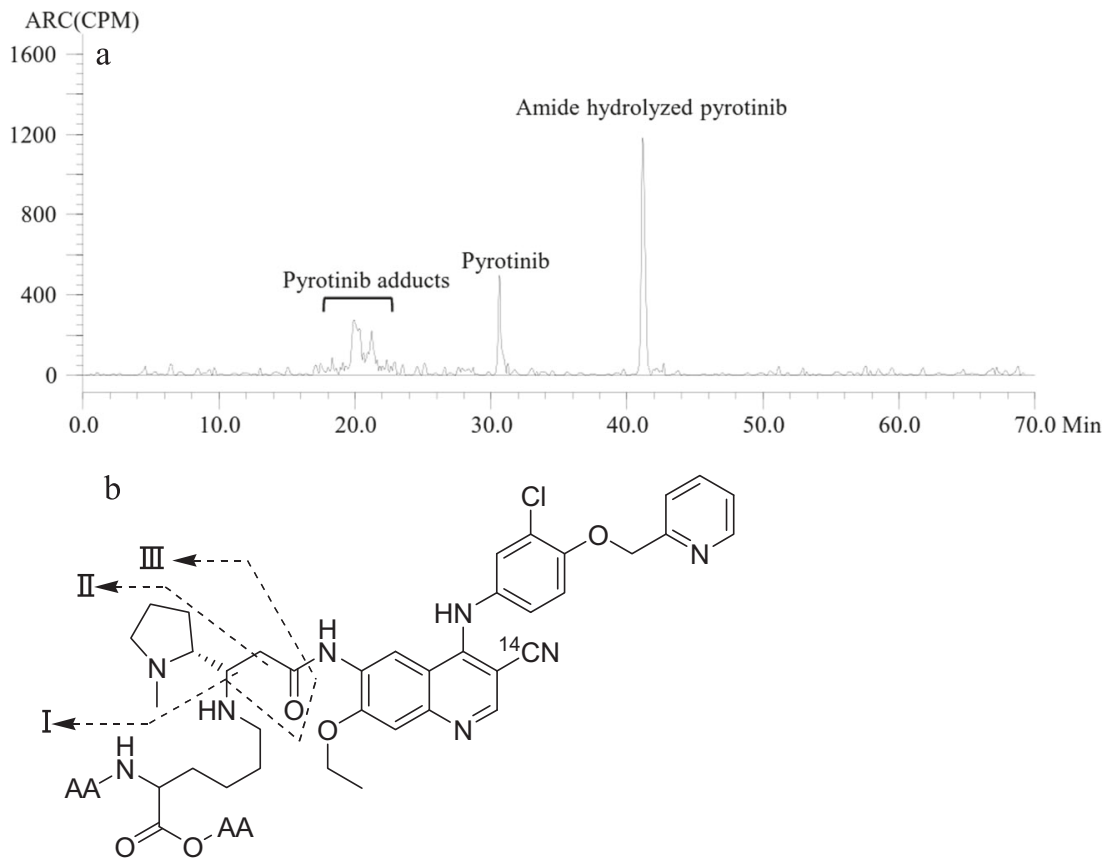

Fig. 5 Radiochromatogram of human plasma incubated with $\left[{ }^{14} \mathrm{C}\right]$ pyrotinib for $24 \mathrm{~h}$ after $\mathrm{HCl}$ hydrolysis (a) and proposed fragmentation pathways of $\left[{ }^{14} \mathrm{C}\right]$ pyrotinib peptide adducts $(\mathbf{b})$. $A A$, the amino acid residues

Table 5. Mass spectral data of radioactive $\left[{ }^{14} \mathrm{C}\right]$ pyrotinib peptide adducts obtained by $\mathrm{HCl}$ hydrolysis of human plasma incubated with $\left[{ }^{14} \mathrm{C}\right]$ pyrotinib for $24 \mathrm{~h}$

\begin{tabular}{|c|c|c|}
\hline$\left[{ }^{14} \mathrm{C}\right]$ Pyrotinib adducts & {$[\mathrm{M}+\mathrm{H}]^{+}, m / z$} & Characteristic fragment ions, $\mathrm{m} / \mathrm{z}^{\mathrm{a}}$ \\
\hline Gly-Lys* & 788.3448 & 585.2174 (I), 299.2056 (II), 138.0905 (III) \\
\hline Gly-Lys*-Ala & 859.3845 & $585.2240(\mathrm{I}), 370.2442$ (II), 138.0902 (III) \\
\hline Lys*-Ala-Ser & 889.3903 & 585.2160 (I), 400.2536 (II), 138.0886 (III) \\
\hline
\end{tabular}

* the AA residue to which pyrotnib is bound

al, II and III in the brackets indicate the fragmentation pathway of product ion formation (see Figure $5 \mathrm{~b}$ )

Table 6. Time course of pyrotinib recovery after incubation with human plasma and resuspension with phosphate buffer, $\mathrm{pH} 7.4$

\begin{tabular}{lll}
\hline Incubation time $(\mathrm{h})$ & Concentration $(\mu \mathrm{g} / \mathrm{mL})$ & Recovery $(\%)^{\mathrm{a}}$ \\
\hline 0 & 20.5 & 103 \\
6 & 16.6 & 83.0 \\
\hline Reconstitution time $(\mathrm{h})$ & Concentration $(\mu \mathrm{g} / \mathrm{mL})$ & Recovery $(\%)^{\mathrm{b}}$ \\
\hline 0 & 0.0336 & 0.988 \\
16 & 0.715 & 21.0 \\
\hline
\end{tabular}

a percentage of extractable pyrotinib accounting for pyrotinib added into human plasma

percentage of pyrotinib recovered after resuspension with phosphate buffer accounting for pyrotinib covalently bound with human plasma

\section{ACKNOWLEDGEMENTS}

This work was partially supported by the National Natural Science Foundation of China (No 81521005), the Strategic Priority Research Program of the Chinese Academy of Sciences (No XDA12050306), the National Key New Drug Creation Special Programs (No 2017ZX09304-021), Jiangsu Provincial Medical Youth Talent (QNRC2016714), National Natural Science Foundation of China (No.81773820), the Jiangsu Provincial Medical Talent (ZDRCA2016048) and the Suzhou Key Laboratory of Drug Clinical Research and Personalized Medicine (SZS201719).

\section{AUTHOR CONTRIBUTION}

$J M, X Y C, D F Z$, and LYM were responsible for study design and data analyses. JM, X-YL, SMA, HZ, SDY, YFZ, MXC, XYZ, YL, LY, and XLD conducted the study. YFZ conducted data analyses. JM and DFZ were responsible for writing the manuscript.

\section{ADDITIONAL INFORMATION}

Competing interests: The authors declare that there is no competing interests. 


\section{REFERENCES}

1. Li X, Yang CY, Wan H, Zhang G, Feng J, Zhang L, et al. Discovery and development of pyrotinib: a novel irreversible EGFR/HER2 dual tyrosine kinase inhibitor with favorable safety profiles for the treatment of breast cancer. Eur J Pharm Sci. 2017;110:51-61.

2. Ma F, Li Q, Chen SS, Zhu WJ, Fan Y, Wang JY, et al. Phase I study and biomarker analysis of pyrotinib, a novel irreversible Pan-ErbB receptor tyrosine kinase inhibitor, in patients with human epidermal growth factor receptor 2-positive metastatic breast cancer. J Clin Oncol. 2017;35:3105-12.

3. Zhu YT, Li L, Zhang G, Wan H, Yang CY, Diao XX, et al. Metabolic characterization of pyrotinib in humans by ultra-performance liquid chromatography/quadrupole time-of-flight mass spectrometry. J Chromatogr B. 2016;1033-1034:117-27.

4. Johnson DS, Weerapana E, Cravatt BF. Strategies for discovering and derisking covalent, irreversible enzyme inhibitors. Future Med Chem. 2010;2:949-64.

5. Singh J, Petter RC, Baillie TA, Whitty A. The resurgence of covalent drugs. Nat Rev Drug Discov. 2011;10:307-17.

6. Kalgutkar AS, Dalvie DK. Drug discovery for a new generation of covalent drugs. Expert Opin Drug Discov. 2012;7:561-81.

7. Mah R, Thomas JR, Shafer CM. Drug discovery considerations in the development of covalent inhibitors. Bioorg Med Chem Lett. 2014;24:33-9.

8. Hossam M, Lasheen DS, Abouzid KAM. Covalent EGFR inhibitors: binding mechanisms, synthetic approaches, and clinical profiles. Arch Pharm Chem Life Sci. 2016;349:573-93.

9. Cheng $\mathrm{H}$, Nair SK, Murray BW. Recent progress on third generation covalent EGFR inhibitors. Bioorg Med Chem Lett. 2016;26:1861-8.

10. Lacy S, Hsu B, Miles D, Dana A, Wang R, Nguye L.Metabolism and disposition of cabozantinib in healthy male volunteers and pharmacologic characterization of its major metabolites.Drug Metab Dispos. 2015;43:1190-207.

11. US Department of Health and Human Services. Common Terminology Criteria for Adverse Events (CTCAE) Version 4.03. Bethesda, MD: National Institutes of Health; 2010.

12. Imbs DC, Paludetto $M N$, Négrier $S$, Powell $H$, Lafont $T$, White-Koning $M$, et al. Determination of unbound fraction of pazopanib in vitro and in cancer patients reveals albumin as the main binding site. Invest New Drugs. 2016;34:41-8.

13. Yeggoni DP, Manidhar DM, Suresh Reddy C, Subramanyam R. Investigation of binding mechanism of novel 8-substituted coumarin derivatives with human serum albumin and a-1-glycoprotein. J Biomol Struct Dyn. 2016;34: 2023-36.

14. Smith SA, Gagnon S, Waters NJ. Mechanistic investigations into the species differences in pinometostat clearance: impact of binding to alpha-1-acid glycoprotein and permeability-limited hepatic uptake. Xenobiotica. 2017;47:185-93.

15. Chandrasekaran A, Shen L, Lockhead S, Oganesian A, Wang JY, Scatina J. Reversible covalent binding of neratinib to human serum albumin in vitro. Drug Metab Lett. 2010;4:220-7.

16. Zhang D, Krishna R, Wang L, Zeng J, Mitroka J, Dai R, et al. Metabolism, pharmacokinetics, and protein covalent binding of radiolabeled MaxiPost (BMS204352) in humans. Drug Metab Dispos. 2005;33:83-93.

17. Wang JY, Li-Chan XX, Atherton J, Deng L, Espina R, Yu L, et al. Characterization of HKI-272 covalent binding to human serum albumin. Drug Metab Dispos. 2010;38:1083-93.

18. Scheers E, Leclercq L, Jong JD, Bode N, Bockx M, Laenen A, et al. Absorption, metabolism, and excretion of oral ${ }^{14} \mathrm{C}$ radiolabeled ibrutinib: an open-label, phase I, single-dose study in healthy men. Drug Metab Dispos. 2015;43:289-97.

19. Dickinson PA, Cantarini MV, Collier J, Frewer P, Martin S, Pickup K, et al. Metabolic disposition of osimertinib in rats, dogs, and humans: insights into a drug designed to bind covalently to a cysteine residue of epidermal growth factor receptor. Drug Metab Dispos. 2016;44:1201-12.

20. Schreiber G, Urban J, Zahringer J, Reutter W, Frosch U. The secretion of serum protein and the synthesis of albumin and total protein in regenerating rat liver. J Biol Chem. 1970;246:4531-8.

21. Yang B, Kim JC, Seong J, Tae G. Comparative studies of the serum half-life extension of a protein via site-specific conjugation to a species-matched or -mismatched albumin. Biomater Sci. 2018;6:2092-100.

22. Narita N, Morohashi A, Tohyama K, Takeuchi T, Tagawa $\mathrm{Y}$, Kondo $\mathrm{T}$, et al. Mechanism for covalent binding of MLN3126, an oral chemokine C-C motif receptor 9 antagonist, to serum albumins. Drug Metab Dispos. 2018;46:204-13.

23. Reed RG, Davison LK, Burrington CM, Peters T Jr. Non-resolving jaundice: bilirubin covalently attached to serum albumin circulates with the same metabolic half-life as albumin. Clin Chem. 1988;34:1992-4.

24. Johansson $\mathrm{MH}$. Reversible michael additions: covalent inhibitors and prodrugs. Mini Rev Med Chem. 2012;12:1330-44. 